\title{
Prediction Of Playfulness By Pretend Play, Severity Of Autism Behaviors, And Verbal Comprehension In Children With Autism Spectrum Disorder
}

This article was published in the following Dove Press journal: Neuropsychiatric Disease and Treatment

\author{
Kuan-Lin Chen (1D) ${ }^{1-3}$ \\ Cheng-Te Chen ${ }^{4}$ \\ Chien-Ho Lin $^{5}$ \\ Chien-Yu Huang ${ }^{6}$ \\ Ya-Chen Lee ${ }^{7}$
}

'Department of Occupational Therapy, College of Medicine, National Cheng Kung University, Tainan City 70I, Taiwan (R.O.C); ${ }^{2}$ Department of Physical Medicine and Rehabilitation, National Cheng Kung University Hospital, College of Medicine, National Cheng Kung University, Tainan City 70I, Taiwan (R.O. C); ${ }^{3}$ Institute of Allied Health Sciences, College of Medicine, National Cheng Kung University, Tainan City 70I, Taiwan (R.O.C); ${ }^{4}$ Department of Educational Psychology and Counseling, National Tsing Hua University, Hsinchu, Taiwan (R. O.C); ${ }^{5}$ Department of Psychiatry, Chi Mei Medical Center, Youngkang Dist., Tainan City 7I0, Taiwan (R.O.C); ${ }^{6}$ Department of Occupational Therapy, I-Shou University, Yanchao District, Kaohsiung City 824, Taiwan (R.O.C); ${ }^{7}$ Department of Occupational Therapy, College of Medical and Health Science, Asia University, Wufeng, Taichung, Taiwan (R. O.C)
Correspondence: Ya-Chen Lee Department of Occupational Therapy, College of Medical and Health Science, Asia University, No. 500, Lioufeng Road, Wufeng, Taichung, Taiwan (R.O.C) Tel +886-4-23323456 Ext. 20007 Email jennyleenet@hotmail.com
Background: Children with autism spectrum disorder (ASD) often exhibit deficits in pretend play and have less playfulness. The purpose of this study was to evaluate the relationship between pretend play and playfulness in children with autism spectrum disorder, while controlling for severity of autism behaviors, verbal comprehension, and age.

Methods: A sample of 72 children with ASD aged between 3 and 12 years were assessed with the Child-Initiated Pretend Play Assessment, Test of Playfulness, and Childhood Autism Rating Scale, respectively, for their pretend play, playfulness, and severity of autism behaviors. Correlation and multiple regression analyses were conducted.

Results: The results of Pearson correlation coefficients revealed that the pretend play variables had mild to moderate associations with the playfulness variables $(r=-0.25$ to 0.68$)$. The multiple regression analyses showed that, overall, the internal locus of control was the significant predictor of the pretend play variables (accounting for $5-47 \%$ of the variance, $p<0.001$ ). The six pretend play variables were all important predictors of all playfulness variables (explaining $41-$ $76 \%$ of the variance, $p<0.001-0.047$ ). Particularly, the elaborate pretend play action was a significant predictor of all four playfulness variables. Our findings indicated that the more children with ASD engaged in pretend play, the more they experienced playfulness.

Conclusion: Clinicians could help children with ASD improve their feeling of being in charge of their play in order to develop better performance in pretend play. Assisting children with ASD to engage in pretend play is important to promote their internal experience of playfulness.

Keywords: autism spectrum disorder, pretend play, playfulness, severity of autism behaviors

\section{Introduction}

Play is an important component of children's occupation, ${ }^{1}$ and it both reflects and contributes to the development of their physical, cognitive, and social skills. ${ }^{2,3}$ Play can be divided into external performance and internal experience. ${ }^{4,5}$ The external performance is the play behavior observed through play activities. The internal experience, known as playfulness, represents the quality of play and is significantly related to the internal character traits of a child. ${ }^{6}$ In other words, the external performance of play, such as pretend play, provides children the opportunity to act out their internal experiences (e.g., how a child feels in play). Thus, considering both external performance and internal experience (playfulness) can lead to a more comprehensive description of play and contribute to deeper understanding of the attributes of play.

Pretend play, a crucial component of children's development, ${ }^{7}$ is a representation of the external performance of play. Pretend play by definition involves escaping into 
make-believe and incorporates both conventional-imaginative play and symbolic play. ${ }^{7}$ Conventional-imaginative play refers to the perception of objects as real and their employment in ways that indicate their function, ${ }^{7,8}$ such as a child using a toy spoon to feed a doll. Symbolic play is that which involves using objects as something else (eg, using a banana as a telephone), attributing properties to objects (eg, pretending a doll is dirty), or pretending an absent object is present (eg, holding an absent toothbrush). ${ }^{7,8}$ Engaging in pretend play allows children unique opportunities to learn daily and social skills such as communication, problem-solving, and empathy. ${ }^{8}$

Playfulness, the internal experience of play, exists in any form of play performance. Playfulness is a key component in determining both the status of an activity as play or not play and the quality of the play experience. ${ }^{9}$ Skard and Bundy (2008) identify four elements of playfulness: internal locus of control, intrinsic motivation, suspension of reality, and framing. ${ }^{10}$ Internal locus of control is the term for the child's ability to choose the "how", "who", "where", and "what" of the play actions. For example, in play, a child decides whether or not to expend extra effort to meet a challenge. Intrinsic motivation refers to a child engaging in an activity simply to enjoy it, rather than to receive external rewards. For example, the play involves paying more attention to the process than to the product. Suspension of reality refers to the child's ability to bring non-literal, fantasy elements into play. For example, the usual meanings of objects are no longer applied in play. Framing is the child's ability to give and read social cues and interact with others, ${ }^{11,12}$ such as the social interactions between a mother and a child in make-believe play. These four elements interact with each other and contribute to the playfulness of a child. When a child feels self-controlled, self-motivated, and free from reality, and the child is able to interact with others in play, it is believed that the child is playful and experiencing play. Playfulness provides motivation for learning. When a child is playful during play, the child can learn best through active experiences with people, materials and ideas, all of which benefit child development. ${ }^{11}$

Pretend play and playfulness are two different constructs, but they exist simultaneously and are complementary to each other. A child in a stimulating play environment of toys may exhibit symbolic play skills; however, the child might not feel self-controlled or self-motivated in play. On the other hand, a child may feel playful even if he or she cannot understand the pretend actions of play. Therefore, simultaneous assessment of pretend play and playfulness allows researchers to gain insights into how the two constructs interact, which in turn increase understanding of the play patterns of children.

It has been reported that children with autism spectrum disorder (ASD) often exhibit deficits in pretend play and have less playfulness. ${ }^{13}$ Children with ASD have been reported to have restricted repetitive and stereotyped patterns of behavior, restricted interests, and a lack of complexity and diversity in play. ${ }^{14}$ In a review of literature about pretend play in children with ASD, Jarrold (2003) concluded that children with ASD have a tendency not to engage in pretend play or have marked difficulty in producing pretend play. For example, symbolism, creativity, and complexity in play might be absent in children with ASD. ${ }^{15}$ As regards playfulness, Skaines and colleagues (2006) reported that children with ASD were less playful in play than their typically developing peers in both unstructured and structured (e.g., with adult facilitation) conditions. ${ }^{6}$ These studies have provided preliminary evidence that children with ASD have pretended play and playfulness deficits.

In a previous study of pretend play and playfulness, a relationship between pretend play and playfulness in children with ASD, developmental delay, and typical development was reported. ${ }^{16}$ However, the association was estimated from a rather small sample size of children with ASD $(n=20)$, which might have limited the statistical power of the results. A larger sample size would allow for more accurate interpretations of the associations between pretend play and playfulness. Additionally, it has been reported that the severity of autism behaviors, verbal comprehension, and age might have impacts on a child's pretend play skills or internal experience of play. ${ }^{6,17,18}$ It is important to take into account the influence of severity of autism behaviors, verbal comprehension, and age to determine the specific play deficits in children with ASD. Therefore, the purpose of this study was to examine the relationship between pretend play and playfulness in children with ASD with a larger sample size, while controlling for the severity of autism behaviors, verbal comprehension, and age.

\section{Methods}

\section{Participants}

Children with ASD aged between 3 and 12 years were recruited from three hospitals and six clinics of pediatric rehabilitation in southern Taiwan. The inclusion criterion was a diagnosis of autistic disorder or Asperger's disorder based on the diagnostic criteria of the Diagnostic and Statistical Manual of Mental Disorders, Fourth edition, Text Revision (the DSMIV-TR), or a diagnosis of ASD according to the DSM $-5^{19}$ made 
by a trained psychiatrist or pediatrician. Furthermore, before participating in our study, the diagnosis of the ASD was also confirmed with the Childhood Autism Rating Scale (CARS), with a cut-off point of 25.5 indicating the presence of symptoms of ASD. ${ }^{20}$ The participants were excluded if they: (1) had uncorrected hearing or visual impairment and (2) had symptoms associated with organic brain dysfunction (e.g., seizures, cerebral palsy) or chromosomal abnormality (e.g., Down syndrome).

This study was approved by the institutional review boards of National Cheng Kung University Hospital (reference number: B-R-104-094) and conducted in accordance with the Declaration of Helsinki. Written informed consent was obtained from each child's caregiver and from children aged 7 or above.

\section{Measures}

\section{Pretend Play: Child-Initiated Pretend Play Assessment} (ChIPPA)

The ChIPPA ${ }^{21,22}$ was used to assess the abilities of the participants to initiate and engage in pretend play. Assessment with the ChIPPA consists of two sessions. In these sessions, one for assessing conventional-imaginative play and one for assessing symbolic play, two sets of appropriate play materials are provided to the child. For conventional-imaginative play, the toys are a farm set, and for symbolic play, they are nonconventional play materials. ${ }^{21}$ The administration of the ChIPPA is referred to as the "pretend play condition" in this study. When each session begins, the child can play freely with the objects. The assessor then uses a "doll" toy to model five play actions, and the child is again allowed and encouraged to play freely with the objects. $^{22}$

In the pretend play condition, the children were scored on three items: the percentage of elaborate pretend actions (PEPA), the number of object substitutions (NOS), and the number of imitated actions (NIA). The PEPA captures the process of a child's self-imitated play, as well as the level of organization and complexity. The PEPA is calculated by dividing the number of elaborate play actions by the total actions in each session of the ChIPPA. The NOS refers to the number of times a child uses an object in substitution during play. The NIA represents the number of times the child imitates the modelled actions. ${ }^{22,23}$ Since the ChIPPA has two play sessions (the conventional-imaginative play session and the symbolic play session), three items are scored for each play session. Thus, six play scores (i.e., PEPA-conventional, PEPA-symbolic, NOS-conventional, NOS-symbolic, NIA-conventional, and NIA-symbolic) were calculated for each ChIPPA assessment in the current study. ${ }^{22}$ Higher scores represent more pretend play skills, except for NIA items (i.e., NIAconventional, and NIA-symbolic), which are reverse scored such that higher scores indicate weaker pretend play skills.

The validity and reliability of the ChIPPA have been well established. The ChIPPA has good content validity and construct validity. ${ }^{23}$ The test-retest reliability of the ChIPPA is moderate to good (intraclass correlation coefficient $=0.57-0.85$ ) and the inter-rater agreement is high $(r=0.81-0.90) .{ }^{22-24}$ The ChIPPA is reported to be able to distinguish between typically developing children and those with pre-academic problems. Furthermore, the inter-rater agreement of the ChIPPA domains, which was estimated from 10 videos for the current study, ranged from $81 \%$ to $90 \%$.

\section{Playfulness: Test Of Playfulness (ToP)}

The ToP (version 4$)^{6}$ was used to assess the participants' playfulness. ${ }^{6}$ The ToP is an observational assessment and designed to be scored from videotapes of children engaging in 15 mins of free play with toys. ${ }^{11}$ The administration of the ToP is referred to as the "free play condition" in this study. The ToP consists of 21 items for assessing four elements: internal locus of control, intrinsic motivation, suspension of reality, and framing. Each item is scored on a 4-point scale of 0 to 3 that reflects the extent (i.e., proportion of time), intensity (i.e., degree of presence), or skill (i.e., ease of performance) of a child in free play. ${ }^{11}$ In the present study, the toys were selected and arranged in accordance with the ToP guidelines, and they were classified into four categories: sensorimotor play, constructive play, pretend play, and board game (Table 1). ${ }^{11}$

The ToP has been reported to have good construct validity (e.g., data from 93\% items and 98\% of people fit the Rasch expectations). ${ }^{11}$ The ToP has excellent interrater reliability and moderate test-retest reliability (i.e., ICC $=0.67) .^{25}$ Furthermore, the inter-rater agreement of the ToP domains, which was estimated from 10 videos for the current study, ranged from $86 \%$ to $90 \%$.

\section{Severity Of Autism Behaviors: Childhood Autism Rating Scale (CARS)}

The $\mathrm{CARS}^{26}$ was used to assess the severity of autism behaviors. $^{26}$ The CARS is a 15 -item behavioral rating scale targeting autistic behaviors, such as relatedness to others, body use, verbal and nonverbal communication, and object use. In this study, the CARS was completed by caregiver interview. Each item is rated on a scale from 1 (normal) to 4 (severely abnormal), with a total score ranging from 15 to 60 . Higher scores indicate greater severity of the behavior specified. This 
Table I Play Materials Used In The Free Play Condition (as Measured By The Test Of Playfulness)

\begin{tabular}{|l|l|}
\hline Play Category & Play Objects \\
\hline Sensorimotor play & $\begin{array}{l}\text { Rody horse } \\
\text { Large tactile ball } \\
\text { I5 in I music box }\end{array}$ \\
\hline Constructive play & $\begin{array}{l}\text { Box of string beads } \\
\text { Drawing board } \\
\text { Puzzle with frame } \\
\text { Puzzle without frame } \\
\text { Tube sorting } \\
\text { Snowflakes connecting } \\
\text { Clay set (clay, tools) } \\
\text { Lego } \\
\text { Wooden building block } \\
\text { Plastic screw toy set }\end{array}$ \\
\hline Pretend play & $\begin{array}{l}\text { Doctor set } \\
\text { Baseball set (bat, baseball) } \\
\text { Box of rubber animals } \\
\text { Cars and truck without tracks } \\
\text { Cars with tracks } \\
\text { Kitchen set } \\
\text { Transforming robots }\end{array}$ \\
\hline Foard games & $\begin{array}{l}\text { Foker cards } \\
\text { Jenga } \\
\text { "UNO" cards } \\
\text { "SHARK ALARM" game }\end{array}$ \\
\hline
\end{tabular}

tool typically has a cut-off score of 30 or higher to indicate ASD. ${ }^{27}$ Mayes et al (2011) suggested that with a lower cut-off score of 25.5, the results are more accurate for differentiating high functioning autism (HFA) from autistic disorder. ${ }^{28}$ Therefore, in this study, a CARS cut-off point of 25.5 was adopted, and a score of below 25.5 meant the child did not meet the clinical threshold considered to indicate symptoms of ASD. $^{20}$ The CARS has been reported to have a split-half reliability of $0.85 .^{29}$ The test-retest reliability and inter-rater reliability of the CARS are good (kappa $=0.88$ and $\mathrm{ICC}=$ 0.71 , respectively). ${ }^{26}$ In addition, the CARS has moderate convergent validity with the Binet-Kamat Test of Intelligence $(r=0.42)$ and divergent validity $(r=-0.18)$ with the ADD-H Comprehensive Teacher Rating Scale. ${ }^{27}$

Verbal ability: The Verbal Comprehension Index (VCI) of the Wechsler Preschool and Primary Scale of Intelligence, Fourth Edition (WPPSI-IV ${ }^{\mathrm{TM}}$ ) or Wechsler Intelligence Scale for Children, Fourth Edition (WISC-IV ${ }^{\mathrm{TM}}$ )

The VCI of the WPPSI-IV ${ }^{\mathrm{TM}}$ or WISC-IV ${ }^{\mathrm{TM} 30}$ was used in this study to assess children's verbal comprehension. ${ }^{30}$ The
VCI of the WPPSI-IV was used to assess children aged from 2 years 6 months to 7 years 7 months and contains the subtests of Information and Similarities. The VCI of the WISC-IV was used to assess children aged from 6 years old to 16 years old 11 months and contains the subtests of Vocabulary, Similarities, and Comprehension. The VIC of the WPPSI-VI or WISC-IV was individually administered to the children and completed by paper-and-pencil. The VCIs of the WPPSI-IV and WISCIV have been reported to have good psychometric properties. For the VCI of the WPPSI-IV, the test-retest reliability ranges from 0.72 to 0.89 and the construct validity is good. ${ }^{31}$ For the VCI of the WISC-IV, the average reliability coefficient is 0.94 , the test-retest reliability coefficient ranges from 0.89 to $0.93,{ }^{31}$ and the construct validity is good. ${ }^{32}$

\section{Procedures}

Prior to the study, the knowledge and skills needed to use the assessments (i.e., the ChIPPA, the ToP, the CARS, the WPPSI-IV $^{\mathrm{TM}}$, and the WISC-IV ${ }^{\mathrm{TM}}$ ) had been provided to the assessor and coder (both occupational therapists). The assessor practiced with an experienced therapist several times and finished a pilot study under supervision. The assessor was allowed to begin formal recruitment when the experienced therapist approved her assessment skills. The assessor performed all the assessments but was excluded from the coding sessions of the ChIPPA and ToP. The coder, who was blind to the status of the participants (e.g., severity of ASD) and did not know the hypothesis of the study, was responsible for coding the sessions of the two play conditions by watching the video recordings. During the study periods, the assessor and coder discussed neither the evaluation processes nor the results of the participants to avoid potential biases.

The data of each participant were collected in two visits separated by two weeks. Depending on the age of the child, either the WPPSI-IV ${ }^{\mathrm{TM}}$ or the WISC-IV ${ }^{\mathrm{TM}}$ was administered to the child before he or she entered the play sessions. The caregivers filled out the basic information sheet and were interviewed with the CARS. The caregivers and assessor were present throughout each play observation session. All play, whether in the pretend play condition (the ChIPPA) or the free play condition (the ToP), was videotaped for subsequent rating by the coder.

\section{Statistical Analysis}

Descriptive statistics were used to describe the chronological age, severity of autism behaviors, and verbal ability of each participant. Pearson correlation coefficients $(r)$ were used first 
to examine the correlations between the six pretend play variables (PEPA-conventional, PEPA-symbolic, NOS-conventional, NOS-symbolic, NIA-conventional, and NIA-symbolic) and the four playfulness variables (internal locus of control, intrinsic motivation, suspension of reality, and framing). An $r$ value $>0.75$ indicates strong correlation; values of 0.50 to 0.75 represent moderate correlation; values of 0.25 to 0.50 indicate small correlation; and values of $\leq 0.25$ indicate weak correlation. ${ }^{33}$

Multiple regression analyses were carried out to investigate the correlations between pretend play and playfulness, while controlling for the severity of autism behaviors, verbal comprehension, and age. Each of the pretend play variables was treated as a dependent variable predicted by all playfulness variables and its two-way interactions, and vice versa. Therefore, a total of ten regression analyses were conducted, and the stepwise approach was used for model selection. The nominal significance level was set at 0.05 . The alpha level was not adjusted because this study was intended to be an exploratory study of relationships between pretend play and playfulness. We did not conduct a correction for fear of missing any potentially meaningful findings. In addition, although correction (e.g., Bonferroni correction) can reduce the chances of obtaining type I error, type I error cannot be reduced without inflating type II error. ${ }^{34-36}$ Thus, the correction might have severely reduced our power to detect important relationships between the variables of pretend play and playfulness. Data were analyzed in SPSS 17.0 for Windows.

\section{Results}

A total of 72 children participated in the study. The mean age was 73.83 months, and $86.1 \%$ of the participants were boys (Table 2). The mean VCI scores of the WPPSI-IV ${ }^{\mathrm{TM}}$ / WISCI-IV $^{\mathrm{TM}}$ and CARS were $89.68(\mathrm{SD}=22.62)$ and $32.25(\mathrm{SD}=3.65)$, respectively, indicating that on average, our participants had moderate verbal comprehension with high symptom severity of autism behaviors. The Pearson correlation coefficients $(r)$ of pretend play and playfulness revealed a number of significant correlations (Table 3 ). PEPA-conventional, PEPA-symbolic, and NOS-symbolic had small to moderate ( $r=0.46$ to 0.68 ) positive correlations with all of the variables of playfulness (i.e., internal locus of control, intrinsic motivation, suspension of reality, and framing). Significant, small ( $r=0.28$ to 0.31 ), and positive correlations were found between NOS-conventional and three variables of playfulness (i.e., internal locus of control, intrinsic motivation, and framing). NIAconventional was significantly negatively correlated with
Table 2 Characteristics Of The Participants $(\mathrm{N}=72)$

\begin{tabular}{|l|l|l|}
\hline Characteristics & Mean (SD) & Range \\
\hline Sex (boy/girl), n & $62 / 10$ & \\
\hline Chronological age, months & $73.83(25.87)$ & $39-143$ \\
\hline VCl of the WPPSI-IVTM/WISC-IVTM & $89.68(22.62)$ & $45-130$ \\
\hline Childhood Autism Rating Scale & $32.25(3.65)$ & $26-40$ \\
\hline ChIPPA & & \\
PEPA-conventional & $48.90(16.58)$ & $0-77$ \\
PEPA-symbolic & $34.11(18.42)$ & $0-78$ \\
NOS-conventional & $1.00(1.38)$ & $0-6$ \\
NOS-symbolic & $5.14(3.99)$ & $0-15$ \\
NIA-conventional & $0.51(0.92)$ & $0-5$ \\
NIA-symbolic & $1.11(1.25)$ & $0-5$ \\
\hline Test of Playfulness & & \\
Internal locus of control & $20.18(7.24)$ & $6-36$ \\
Intrinsic motivation & $10.31(2.04)$ & $3-14$ \\
Suspension of reality & $7.00(3.79)$ & $0-15$ \\
Framing & $6.28(2.79)$ & $0-12$ \\
\hline
\end{tabular}

Abbreviations: $\mathrm{VCl}$, verbal comprehension index; WPPSI-IV ${ }^{T M}$, Wechsler Preschool and Primary Scale of Intelligence, Fourth Edition; WISC-IV ${ }^{T M}$, Wechsler Intelligence Scale for Children, Fourth Edition; ChIPPA, Child-Initiated Pretend Play Assessment; PEPA, percentage of elaborate pretend actions; NOS, number of object substitutions; NIA, number of imitated actions.

the variable of internal locus of control of playfulness. No significant correlations were found between NIA-symbolic and any of the variables of playfulness.

Table 4 shows the results of the final fitted multiple regressions using each pretend play variable as a dependent variable while controlling for the severity of autism behaviors (i.e., CARS score), verbal comprehension (i.e., VCI, verbal comprehension index), and age. Among the 6 two-way interactions and 4 main effects, intrinsic motivation*framing was a significant predictor of PEPA-conventional, accounting for $47 \%$ of the variance. The internal locus of control was the only significant predictor of PEPA-symbolic, NOS-conventional, and NOS-symbolic, accounting for $47 \%, 8 \%$, and $47 \%$ of the variance, respectively. The internal locus of control*intrinsic motivation was significant predictor of NIA-conventional, accounting for $5 \%$ of the variance. For the last pretend play variable, NIA-symbolic, intrinsic motivation was the only significant predictor, explaining $16 \%$ of the variance.

Table 5 shows the results of the multiple regression analyses treating each of the playfulness variables as a dependent variable, after controlling for the severity of autism behaviors (i.e., CARS score), verbal comprehension (i.e., VCI, verbal comprehension index), and age. The results showed that PEPA-conventional*NOS-symbolic, PEPA- 
Table 3 Correlations Between The Child-Initiated Pretend Play Assessment And Test Of Playfulness In Playfulness In Children With Autism Spectrum Disorder $(\mathrm{N}=72)$

\begin{tabular}{|l|l|l|l|l|}
\hline The Test Of Playfulness & Internal Locus Of Control & Intrinsic Motivation & Suspension Of Reality & Framing \\
\hline ChIPPA & & & & \\
PEPA-conventional & $0.63^{* *}$ & $0.54^{* *}$ & $0.47^{* *}$ & $0.66^{* *}$ \\
PEPA-symbolic & $0.68^{* *}$ & $0.54^{* *}$ & $0.55^{* *}$ & $0.56^{* *}$ \\
NOS-conventional & $0.35^{* *}$ & $0.33^{* *}$ & 0.19 & $0.31^{* *}$ \\
NOS-symbolic & $0.65^{* *}$ & $0.46 * *$ & $0.50^{* *}$ & $0.56^{* *}$ \\
NIA-conventional & $-0.25^{*}$ & -0.21 & -0.15 & -0.23 \\
NIA-symbolic & -0.11 & 0.10 & -0.03 & -0.13 \\
\hline
\end{tabular}

Notes: $* P<0.05 ; * * P<0.01$.

Abbreviations: ChIPPA, Child-Initiated Pretend Play Assessment; PEPA, percentage of elaborate pretend actions; NOS, number of object substitutions; NIA, number of imitated actions.

Table 4 Summary Of The Results Of Multiple Regressions For The Child-Initiated Pretend Play Assessment $(\mathrm{N}=72)$

\begin{tabular}{|c|c|c|c|c|c|}
\hline Regression Model & Predictors & Estimate & $t$-value & $p$-value & $R^{2}$ \\
\hline \multicolumn{6}{|l|}{ ChIPPA } \\
\hline \multirow[t]{5}{*}{ PEPA-conventional } & (constant) & 7.203 & 0.305 & 0.761 & \multirow[t]{5}{*}{0.47} \\
\hline & Age & 0.058 & 1.002 & 0.320 & \\
\hline & $\mathrm{VCl}$ & 0.202 & 2.166 & $0.034 *$ & \\
\hline & CARS & 0.129 & 0.232 & 0.817 & \\
\hline & Intrinsic motivation* Framing & 0.223 & 3.765 & $0.000^{* *}$ & \\
\hline \multirow[t]{5}{*}{ PEPA-symbolic } & (constant) & -30.205 & -1.108 & 0.272 & \multirow[t]{5}{*}{0.47} \\
\hline & Age & 0.110 & 1.645 & 0.105 & \\
\hline & $\mathrm{VCl}$ & 0.023 & 0.223 & 0.825 & \\
\hline & CARS & 0.562 & 0.890 & 0.377 & \\
\hline & Internal locus of control & 1.786 & 5.096 & $0.000 * *$ & \\
\hline \multirow[t]{5}{*}{ NOS-conventional } & (constant) & -2.331 & -0.866 & 0.390 & \multirow[t]{5}{*}{0.08} \\
\hline & Age & -0.002 & -0.286 & 0.776 & \\
\hline & $\mathrm{VCl}$ & 0.003 & 0.313 & 0.755 & \\
\hline & CARS & 0.049 & 0.793 & 0.431 & \\
\hline & Internal locus of control & 0.079 & 2.278 & $0.026 *$ & \\
\hline \multirow[t]{5}{*}{ NOS-symbolic } & (constant) & $3.46 \mathrm{I}$ & 0.552 & 0.583 & \multirow[t]{5}{*}{0.40} \\
\hline & Age & -0.005 & -0.357 & 0.722 & \\
\hline & $\mathrm{VCl}$ & -0.028 & -1.163 & 0.249 & \\
\hline & CARS & -0.099 & -0.683 & 0.497 & \\
\hline & Internal locus of control & 0.385 & 4.765 & $0.000 * *$ & \\
\hline \multirow[t]{5}{*}{ NIA-conventional } & (constant) & 3.742 & 2.106 & 0.039 & \multirow[t]{5}{*}{0.05} \\
\hline & Age & -0.001 & -0.155 & 0.877 & \\
\hline & $\mathrm{VCl}$ & -0.005 & -0.724 & $0.47 I$ & \\
\hline & CARS & -0.064 & -1.526 & 0.132 & \\
\hline & Internal locus of control*Intrinsic motivation & -0.003 & -2.043 & $0.045^{*}$ & \\
\hline \multirow[t]{5}{*}{ NIA-symbolic } & (constant) & -3.384 & -1.356 & 0.180 & \multirow[t]{5}{*}{0.16} \\
\hline & Age & 0.002 & 0.382 & 0.703 & \\
\hline & $\mathrm{VCl}$ & -0.017 & -2.101 & $0.039 *$ & \\
\hline & CARS & 0.100 & 1.901 & 0.062 & \\
\hline & Intrinsic motivation & 0.258 & 2.905 & $0.005^{* *}$ & \\
\hline
\end{tabular}

Notes: $* P<0.05 ; * * P<0.01$.

Abbreviations: ChIPPA, Child-Initiated Pretend Play Assessment; PEPA, percentage of elaborate pretend actions; NOS, number of object substitutions; NIA, number of imitated actions; CARS, Childhood Autism Rating Scale; VCl, Verbal Comprehension Index. 
Table 5 Summary Of The Results Of Multiple Regressions For The Test Of Playfulness $(\mathrm{N}=72)$

\begin{tabular}{|c|c|c|c|c|c|}
\hline Regression Model & Predictors & Estimate & $t$-value & $p$-value & $R^{2}$ \\
\hline Internal locus of control & $\begin{array}{l}\text { (constant) } \\
\text { Age } \\
\text { VCI } \\
\text { CARS } \\
\text { PEPA-symbolic* NOS-symbolic } \\
\text { PEPA-symbolic } \\
\text { PEPA-conventional*NIA-conventional }\end{array}$ & $\begin{array}{l}22.566 \\
0.026 \\
0.084 \\
-0.523 \\
0.008 \\
0.104 \\
-0.030\end{array}$ & $\begin{array}{l}3.296 \\
1.470 \\
3.296 \\
-3.355 \\
3.473 \\
3.265 \\
-2.659\end{array}$ & $\begin{array}{l}0.002 * * \\
0.146 \\
002 * * \\
0.001 * * \\
0.001 * * \\
0.002 * * \\
0.010^{*}\end{array}$ & 0.76 \\
\hline Intrinsic motivation & $\begin{array}{l}\text { (constant) } \\
\text { Age } \\
\text { VCI } \\
\text { CARS } \\
\text { NOS-symbolic*NIA-symbolic } \\
\text { NOS-symbolic*NIA-conventional } \\
\text { PEPA-symbolic }\end{array}$ & $\begin{array}{l}15.330 \\
0.008 \\
0.014 \\
-0.244 \\
0.066 \\
-0.074 \\
0.023\end{array}$ & $\begin{array}{l}5.448 \\
1.133 \\
1.319 \\
-3.909 \\
3.063 \\
-2.615 \\
2.025\end{array}$ & $\begin{array}{l}0.000^{* *} \\
0.261 \\
0.192 \\
0.000^{* *} \\
0.003^{* *} \\
0.011^{*} \\
0.047 *\end{array}$ & 0.53 \\
\hline Suspension of reality & $\begin{array}{l}\text { (constant) } \\
\text { Age } \\
\text { VCI } \\
\text { CARS } \\
\text { PEPA-symbolic }\end{array}$ & $\begin{array}{l}2.358 \\
0.000 \\
0.058 \\
-0.099 \\
0.077\end{array}$ & $\begin{array}{l}0.427 \\
-0.024 \\
2.809 \\
-0.798 \\
3.404\end{array}$ & $\begin{array}{l}0.67 I \\
0.98 I \\
007 * * \\
0.428 \\
0.001 * *\end{array}$ & 0.41 \\
\hline Framing & $\begin{array}{l}\text { (constant) } \\
\text { Age } \\
\text { VCl } \\
\text { CARS } \\
\text { PEPA-conventional } \\
\text { NOS-symbolic }\end{array}$ & $\begin{array}{l}4.525 \\
0.008 \\
0.035 \\
-0.155 \\
0.048 \\
0.138\end{array}$ & $\begin{array}{l}1.288 \\
0.877 \\
2.567 \\
-1.940 \\
2.655 \\
2.063\end{array}$ & $\begin{array}{l}0.202 \\
0.384 \\
0.013^{*} \\
0.057 \\
0.010^{* *} \\
0.043^{*}\end{array}$ & 0.59 \\
\hline
\end{tabular}

Notes: $* P<0.05 ; * * p<0.01$.

Abbreviations: PEPA, percentage of elaborate pretend actions; NOS, number of object substitutions; NIA, number of imitated actions; CARS, Childhood Autism Rating Scale; $\mathrm{VCl}$, Verbal Comprehension Index.

symbolic, and PEPA-conventional*NIA-conventional were significant predictors of the internal locus of control, together contributing $76 \%$ of the variance. One variable of pretend play (i.e., PEPA-symbolic), NOS-symbolic*NIA-symbolic and NOS-symbolic*NIA-conventional was significant main and interaction effects for intrinsic motivation, jointly accounting for $53 \%$ of the variance. The non-significant PEPA-conventional and NOS-symbolic variables were retained due to the presence of corresponding interaction effects. PEPA-symbolic was the only significant predictor of the suspension of reality, accounting for $41 \%$ of the variance. For the last playfulness variable, framing, PEPAconventional and NOS-symbolic were the significant predictors, together contributing $59 \%$ of the variance.

\section{Discussion}

This study aimed to examine the extent of the association of the pretend play performances of children with ASD with their levels of playfulness while considering their severity of autism behaviors, verbal comprehension, and age. The results showed that the pretend play variables had small to moderate associations with the playfulness variables. Additionally, the sense of being in control was an important predictor of most of the pretend play performances, whereas the pretend play variables (i.e., PEPA-conventional, PEPA-symbolic, NOS-conventional, NOS-symbolic, NIA-conventional, or NIA-symbolic) all contributed to the prediction of elements of playfulness. Compared to the previous study, this new model provides a more comprehensive description of play, and our results also show that the external performance and the internal experience are different aspects of play. Clinicians and researchers need to consider both the inter-dependence and the independence of their relationships when treating the play of children with ASD.

Our results showed that elaborate pretend play and the number of substitutions were positively associated with 
most of the variables of playfulness. These findings indicate that the more children with ASD engage in elaborate and complex pretend play and object substitutions, the more internal feelings of playfulness they experience. This finding contradicts a previous report that elaborate pretend play was only associated with the framing variable of playfulness (i.e., giving and receiving social cues regarding interactions with others) in children with ASD. ${ }^{16}$ It is possible that a positive experience gained from engaging in elaborate pretend play and object substitutions creates a sense of enjoyment in children with ASD, and that this sense of enjoyment may encourage them to engage further in self-initiated and symbolic play.

We found that the number of imitated actions was negatively correlated with the variables of internal locus of control. Because the NIA is a reverse-scored item, our results suggest that when children with ASD imitate the actions of others less, they are more likely to feel in charge of their actions, respond more to others' cues, and encourage others to join in the play. ${ }^{6}$ Notably, a previous study found a positive correlation between imitation of actions and suspension of reality, indicating that the more children with ASD imitated others' actions, the less able they were to engage in the suspension of reality. ${ }^{16}$ Our findings add further support to the idea that it is important for children with ASD to self-generate play ideas. It is beneficial for children with ASD to engage in pretend play, as the children become more capable of initiating pretend play themes, their inner control of experiences will improve.

For pretend play performance, after controlling for the severity of autism behaviors, verbal comprehension, and age, the results of regression analysis showed that the variable of internal locus of control was the most important predictor of four variables of pretend play performance. In particular, the internal locus of control was the only significant predictor of the number of object substitutions (in either the conventional imaginative or symbolic play conditions) in pretend play. Internal locus of control gives children with ASD a sense of being in charge of their play behaviors, such as deciding how to play and what to play. For example, in this study, it was observed that children with ASD who displayed the ability to decide how to play and what to do with play objects exhibited more object substitution behaviors in their play. This feeling of being in charge of one's play actions may provide a sense of accomplishment to children with ASD, which may encourage them to use their imaginations to transform objects, give characteristics to objects, and refer to absent objects. ${ }^{37}$ Therefore, our finding demonstrates the importance of taking the internal locus of control into account, as it appears to be significantly related to children's pretend play (particularly the number of object substitutions).

It is worth noting that an interaction effect was found between intrinsic motivation and framing for conventional elaborate pretend play. This finding suggests that the predictive power of intrinsic motivation will be increased if framing is considered with it. As expected, in children with ASD who were more likely to inform a playmate about a play idea and interact with others, the intrinsic motivation was boosted, and they were thus more likely to incorporate logical and sequential organization into play actions. $^{38}$ Therefore, not only intrinsic motivation but also framing is important to children's conventional elaborate pretend play.

For the internal experience of playfulness, after controlling for the severity of autism behaviors, verbal comprehension, and age, the results of the regression analysis showed that the six variables of pretend play (i.e., PEPA, NOS, and NIA, in either the conventional imaginative or symbolic play conditions) contributed to the predictive power of playfulness. The elaborate pretend play, number of object substitutions, and number of imitated actions of pretend play significantly predicted a child's internal locus of control, suggesting that children with more complex and elaborate play, more object substitutions, and less imitation of others' actions have a higher sense of control. It was also observed in clinics that children with ASD who exhibited logical sequencing of play actions, used an object in play and represented that object as something else, and were capable of self-initiating their own play ideas in the conventional-imaginative play tended to be more in charge of how to play. Additionally, elaborate pretend play alone can predict a child's internal freedom to suspend reality to transform objects and to invent imaginary objects. Because elaborate pretend play provides schemas that allow a child to decide how closely the play transactions will represent objective reality, the internal experience of suspension of reality has accordingly been enhanced.

Furthermore, we found that the PEPA variable was a significant predictor for all four playfulness variables. Engaging in elaborate pretend play action allows the child a great deal of locus of control, as elaborate pretend action is characterized by detailed sequences of play action that are organized logically. ${ }^{6}$ During the elaborateness of his/her play, it was observed that the child pretended the doll could sleep and had decided to put the doll to bed. The child used a sheet of paper as blanket to cover the doll. This example of play including logical 
sequential actions might have given the child a tremendous sense of control and boosted his/her intrinsic motivation. As a result, improving the elaborate pretend play action of children with ASD may, in turn, increase their playfulness. For clinicians and caregivers, the findings imply that it is important to provide opportunities for children with ASD to engage in elaboration of play ideas within a play context to foster their internal experience of playfulness.

It is noted that both verbal comprehension and the severity of autism behaviors were more strongly linked to the internal experience of playfulness than to pretend play performance. In particular, the results of the regression model of playfulness showed that verbal comprehension, not severity of autism behaviors, can better predict suspension of reality and framing. Indeed, the important factor related to a child's ability to bring more non-literal, fantasy elements into play and to display more interactions with others during play has been reported to be the child's level of verbal ability. ${ }^{39,40}$ In addition, our findings highlight that the CARS score should be used as intended, that is, to measure the severity of ASD symptoms and not functional impairment. Our study underlines the importance of the inclusion of not only severity of autism behaviors but also verbal comprehension when targeting interventions in children with ASD.

Three limitations of the present study are acknowledged. First, we attempted to avoid potential contamination of the free play condition by the pretend play condition by administering the free play condition first, but the fixed order of test administration may have influenced the results of the study. Future studies employing randomized test order to counterbalance the tests may be needed. Second, the correlation study design did not allow us to make causal inferences from the data. Further studies on longitudinal relations between pretend play performance and the internal experience of playfulness are needed to confirm our correlational findings. Third, the ToP was not conducted in the regular play spaces of the children with ASD, which might have affected the overall scores of the ToP. Future studies will be needed to confirm our results by conducting the ToP in environments familiar to the children.

\section{Conclusion}

The results showed that the inner control of experiences was the important predictor of pretend play performance, while the six pretend play variables were all important predictors of the playfulness variables in children with
ASD. Our findings suggest that it is beneficial for children with ASD to engage in pretend play, for the more the children become capable of initiating pretend play themes, the more inner control of experiences and interactions with others the children will experience. These findings provide useful information that could help clinicians in the process of planning or developing interventions to engage children with ASD in pretend play and thereby to enhance their playfulness.

\section{Acknowledgements}

We are especially thankful to all the caregivers and children for participating in the study. This study was supported by grants awarded to the first author from the Ministry of Science and Technology (103-2410-H-006060, 104-2410-H-006-065, and 104-2811-H-006-009).

\section{Author Contributions}

KLC, CTC, CHL, CYH, YCL formulated the research idea and developed the data analysis plan. KLC, CTC, and YCL performed the data analysis and developed the manuscript. All authors contributed to data analysis, drafting, revising and critically reviewing the article, have given final approval of the version to be published, and agree to be accountable for all aspects of the work.

\section{Disclosure}

The authors report no conflicts of interest in this work.

\section{References}

1. Parham LD, Fazio LS. Play in Occupational Therapy for Children. 2nd ed. St. Louis, MO: Mosby Elsevier; 2008.

2. Piaget J. Play, Dream and Imitation in Childhood. New York: W.W. Norton; 1962.

3. Goldstein J. Play in Children's Development, Health and Well-Being. Brussels: Toy Industries of Europe; 2012.

4. Bundy AC. Assessment of play and leisure: delineation of the problem. Am J Occup Ther. 1993;47(3):217-222. doi:10.5014/ ajot.47.3.217

5. Neumann EA. The Elements of Play. New York: MSS Information; 1971.

6. Skaines N, Rodger S, Bundy A. Playfulness in children with autistic disorder and their typically developing peers. Br J Occup Ther. 2006;69(11):505-512. doi:10.1177/030802260606901104

7. Stagnitti K, Unsworth C. The importance of pretend play in child development: an occupational therapy perspective. Br J Occup Ther. 2000;63(3):121-127. doi:10.1177/030802260006300306

8. Lewis V, Boucher J, Astell A. The assessment of symbolic play in young children: a prototype test. Eur J Disords Commun. 1992;27 (3):231-245. doi:10.3109/13682829209029423

9. Okimoto AM, Bundy A, Hanzlik J. Playfulness in children with and without disability: measurement and intervention. Am J Occup Ther. 2000;54(1):73-82. doi:10.5014/ajot.54.1.73 
10. Skard G, Bundy AC. 4 - test of playfulness. In: Fazio LDPS, editor. Play in Occupational Therapy for Children (second Edition). Saint Louis: Mosby; 2008:71-93.

11. Bundy AC, Nelson L, Metzger M, Bingaman K. Validity and reliability of a test of playfulness. OTJR. 2001;21(4):276-292.

12. Muys V, Rodger S, Bundy AC. Assessment of playfulness in children with autistic disorder: a comparison of the children's playfulness scale and the test of playfulness. OTJR. 2006;26(4):159-170.

13. Jung S, Sainato DM. Teaching play skills to young children with autism. J Intellect Dev Disabil. 2013;38(1):74-90. doi:10.3109/ 13668250.2012 .732220

14. Watt N, Wetherby AM, Barber A, Morgan L. Repetitive and stereotyped behaviors in children with autism spectrum disorders in the second year of life. J Autism Dev Disord. 2008;38(8):1518-1533. doi:10.1007/s10803-007-0532-8

15. Jarrold C. A review of research into pretend play in autism. Autism. 2003;7(4):379-390. doi:10.1177/1362361303007004004

16. Lee Y-C, Chan P-C, Lin S-K, Chen C-T, Huang C-Y, Chen K-L. Correlation patterns between pretend play and playfulness in children with autism spectrum disorder, developmental delay, and typical development. Res Autism Spectr Disord. 2016;24:29-38. doi:10.1016/j.rasd.2016.01.006

17. Stanley GC, Konstantareas MM. Symbolic play in children with autism spectrum disorder. J Autism Dev Disord. 2007;37(7):12151223. doi:10.1007/s10803-006-0263-2

18. Lin SK, Tsai CH, Li HJ, Huang CY, Chen KL. Theory of mind predominantly associated with the quality, not quantity, of pretend play in children with autism spectrum disorder. Eur Child Adolesc Psychiatry. 2017;26(10):1187-1196. doi:10.1007/s00787-017-0973-3

19. American Psychiatric Association. Diagnostic and Statistical Manual of Mental Disorder, Text Revision. 4th ed. Washington, DC: American Psychiatric Association; 2000.

20. Chlebowski C, Green JA, Barton ML, Fein D. Using the childhood autism rating scale to diagnose autism spectrum disorders. J Autism Dev Disord. 2010;40(7):787-799. doi:10.1007/s10803-009-0926-x

21. Stagnitti K, Rodger S, Clarke J. Determining gender-neutral toys for assessment of preschool children's imaginative play. Aust Occup Ther J. 1997;44(3):119-131. doi:10.1111/j.1440-1630.1997.tb00764. $\mathrm{x}$

22. Stagnitti K. Child-Initiated Pretend Play Assessment (chippa). Manual and KIT. Melbourne, Australia: Co-ordinates Publications; 2007.

23. Stagnitti K, Unsworth C. The test-retest reliability of the childinitiated pretend play assessment. Am J Occup Ther. 2004;58 (1):93-99. doi:10.5014/ajot.58.1.93

24. Stagnitti K, Unsworth C, Rodger S. Development of an assessment to identify play behaviours that discriminate between the play of typical preschoolers and preschoolers with pre-academic problems. Can J Occup Ther. 2000;67(5):291-303. doi:10.1177/000841740006700507

25. Brentnall J, Bundy AC, Scott Kay FC. The effect of the length of observation on test of playfulness scores. OTJR. 2008;28:133-140.
26. Schopler E, Reichler RJ, DeVellis RF, Daly K. Toward objective classification of childhood autism: childhood Autism Rating Scale (CARS). J Autism Dev Disord. 1980;10(1):91-103. doi:10.1007/ BF02408436

27. Russell PS, Daniel A, Russell S, et al. Diagnostic accuracy, reliability and validity of Childhood Autism Rating Scale in India. World $J$ Pediatr. 2010;6(2):141-147. doi:10.1007/s12519-010-0029-y

28. Mayes SD, Calhoun SL, Murray MJ, et al. Use of the Childhood Autism Rating Scale (CARS) for children with high functioning autism or asperger syndrome. Focus Autism Other Dev Disabl. 2011;1088357611406902.

29. Tobing LE, Glenwick DS. Relation of the childhood autism rating scale-parent version to diagnosis, stress, and age. Res Dev Disabil. 2002;23(3):211-223. doi:10.1016/S0891-4222(02)00099-9

30. Wechsler D. Wechsler Preschool and Primary Scale of IntelligenceFourth Edition (WPPSI-IV). San Antonio, TX: Pearson Psychological Corporation; 2012.

31. Chen YH, Chen HY. Wechsler Preschool and Primary Scale of Intelligence - Fourth Edition: Chinese Version Manual (wechsler, D.). Taipei, Taiwan: Chinese Behavioral Science Corporation; 2013.

32. Keith T, Fine J, Taub G, Reynolds M, Kranzler J. Higher Order, Multisample, Confirmatory Factor Analysis of the Wechsler Intelligence Scale for Children-Fourth Edition: What Does It Measure? School Psychology Review. 2006;35(1):108-127.

33. Portney LG, Watkins MP. Foundations of Clinical Research: Applications to Practice. 3rd ed. Upper Saddle River: NJ: Pearson Prentice Hall; 2009.

34. Feise RJ. Do multiple outcome measures require p-value adjustment? BMC Med Res Methodol. 2002;2(1):8. doi:10.1186/1471-2288-2-8

35. Hill J, Yajima M. Why we (usually) don't have to worry about multiple comparisons AU - Gelman, Andrew. J Res Educ Eff. 2012;5(2):189-211. doi:10.1080/19345747.2011.618213

36. Rothman KJ. No adjustments are needed for multiple comparisons. Epidemiology. 1990;1(1):43-46. doi:10.1097/00001648-19900100000010

37. Isenberg JP. A position paper of the association for childhood education international play: essential for all children. Childhood Educ. 2002;79:33-39. doi:10.1080/00094056.2002.10522763

38. Uren N, Stagnitti K. Pretend play, social competence and involvement in children aged 5-7 years: the concurrent validity of the childinitiated pretend play assessment. Aust Occup Ther J. 2009;56(1):3340. doi:10.1111/aot.2009.56.issue-1

39. Yogman M, Garner A, Hutchinson J, Hirsh-Pasek K, Golinkoff RM. The power of play: a pediatric role in enhancing development in young children. Pediatrics. 2018;142(3):e20182058. doi:10.1542/ peds.2018-2058

40. Stagnitti K, Lewis FM. Quality of pre-school children's pretend play and subsequent development of semantic organization and narrative re-telling skills. Int $J$ Speech Lang Pathol. 2015;17(2):148-158. doi:10.3109/17549507.2014.941934
Neuropsychiatric Disease and Treatment

\section{Publish your work in this journal}

Neuropsychiatric Disease and Treatment is an international, peerreviewed journal of clinical therapeutics and pharmacology focusing on concise rapid reporting of clinical or pre-clinical studies on a range of neuropsychiatric and neurological disorders. This journal is indexed on PubMed Central, the 'PsycINFO' database and CAS, and is the official journal of The International Neuropsychiatric Association (INA). The manuscript management system is completely online and includes a very quick and fair peer-review system which is all easy to use. Visit http://www.dovepress.com/testimonials.php to read real quotes from published authors. 